\title{
Small airway hyperreactivity among lifelong non-atopic non-smokers exposed to isocyanates
}

\author{
U HJORTSBERG, ${ }^{1}$ P ØRBAK, ${ }^{1}$ M ARBORELIUS Jr ${ }^{2}$ \\ From the Departments of Occupational Medicine, ${ }^{1}$ and Clinical Physiology, ${ }^{2}$ Malmö General Hospital, Sweden
}

ABSTRACT The development of isocyanate asthma is little understood. To gain more knowledge in this area, a group of 20 workers occupationally exposed to isocyanates, five subjects with clinicats isocyanate asthma, and a control group of 10 people not exposed to isocyanate were examined witho lung function tests and a methacholine provocation test. Forced expiratory volume in one secondB and tests aimed at detecting small airways obstruction such as volume of trapped gas, closing volume, and wash out volume were made. To detect abnormal airway reactivity, tests were made் before and after inhalation of methacholine and of salbutamol. A significant increased reactivity toon methacholine in the exposed and asthma groups was seen compared with the control group as measured by volume of trapped gas. The increase was reversed by inhaling salbutamol. In neither? group could a statistically significant reaction be shown in the large airways. The study group had increased small airways reactivity of the same magnitude as the group with isocyanate asthma. Theo subjects in the study group had no clinical symptoms or spirometric abnormalities. The volume of trapped gas in combination with methacholine seems to disclose significantly altered reactivity of the small airways in workers exposed to isocyanate with no subjective symptoms of disease.

Isocyanates even at very low levels, have a sensitising effect on the airways ${ }^{1}$ but most exposed workers have no respiratory symptoms related to their exposure. ${ }^{2}$ It has not been possible to establish any dose-response relation ${ }^{3}$ but about $10 \%$ of workers exposed to toluene diisocyanate (TDI) eventually develop asthma. ${ }^{4}$

Exposure to TDI has been shown to give an annual decline in the forced expiratory flow (FEF $25-75$ and FEF $_{50}$ ) that is greater than in an unexposed population. ${ }^{5}$ Irrespective of symptoms of asthma, workers exposed to TDI have an accelerated decline in lung function as measured by forced expiratory volume in one second $\left(\mathrm{FEV}_{1}\right)^{6}$

Non-specific bronchial hyperreactivity is often found in patients with asthma due to isocyanates. ${ }^{7}$ Bronchial hyperreactivity seems also to be a risk factor for the development of chronic obstructive lung disease. $^{8}$ Among patients with chronic obstructive lung disease small airway changes are often found. ${ }^{9}$

Patients with asthma often have a functional impairment of the small airways that is usually reversible after inhaling bronchodilating drugs. To detect provoked and rapidly reversible asthma in the small airways, $\mathrm{FEV}_{1}$ and maximum flow at $25 \%$ of vital capacity have been found to be less sensitive than the

Accepted 9 March 1987 volume of trapped gas (VTG). ${ }^{10}$ Subjective symp:toms may be absent until obstructive changes in lape airways occur, since small airway disease does not in crease resistance to breathing.

The purpose of the present study was to search fo small airway hyperreactivity among symptom free workers exposed to isocyanate. The demonstration of hyperreactivity at very low exposure is important fo the setting of hygienic limit values for isocyanates? Our hypothesis was that isocyanates might cause. hyperreactivity in the small airways and that the changes in reactivity could be detected before ang subjective symptoms had appeared.

The method used for measuring the $\mathrm{VTG}^{11}$ has been shown to be sensitive to abnormalities in the small airways. ${ }^{12}$ By combining the VTG method wit倹 methacholine inhalation we hoped to increase the sene sitivity for detecting abnormal reactivity in small airs ways. To study the reversibility of obstruction i small airways VTG was also measured before and after inhalation of the $\beta_{2}$ agonist salbutamos (Ventoline, Glaxo).

\section{Material}

The study group $(\mathrm{n}=20 ; 20-56$ years) consisted of men exposed to isocyanates at their workplaces ime 
Malmö. They had been exposed to isocyanates in different work procedures such as insulation of heating pipes, spray painting of vehicles, and polyurethane glueing. The local unions helped select the study group. They were informed that we wished to study workers with no respiratory symptoms. The union safety officers supplied us with lists of workers who had never smoked and were exposed to isocyanates. The size of the study group was limited by difficulties in finding workers who had never smoked. Initially 24 workers were referred, four of whom were not included in the final group. The reasons for exclusion were in one a family history of asthma and raised total $\mathrm{IgE}$, in the second seven positive skin prick tests to common allergens, in the third pleurisy, past lung inflammation, and exposure to asbestos, and in the fourth inability to participate because of allergic symptoms.

The subjects in the study group all considered themselves healthy and had no respiratory symptoms. None had any history of asthma or other allergic disease or a family history of such diseases. They thus constituted a healthy sample of workers exposed to isocyanate.

The control group $(\mathrm{n}=10 ; 24-41$ years) comprised non-smoking men with no previous lung disease or history of asthma or allergy. They had no contact with isocyanates or other lung irritating agents. For the closing volume measurements, equipment failure reduced the control group to only three subjects.

We also re-examined five subjects (aged 19-48) diagnosed as having asthma induced or worsened by exposure to isocyanate. The diagnosis was made by clinical signs of asthma and at least $20 \%$ decrease of $\mathrm{FEV}_{1}$ at methacholine inhalation. All were smokers and had been removed from further exposure to isocyanates for at least one year before the present examination and were free from symptoms of asthma at the time of examination.

The study and control groups were comparable with regard to age, height, and results of blood tests such as total IgE, eosinophil leukocytes, and total leukocytes.

The group with asthma had more eosinophil leukocytes $\left(\right.$ mean $\left.=190^{*} 10^{6} / 1\right)$ than the control (mean $=$ $\left.77^{*} 10^{6} / 1\right)$ and study (mean $\left.=104^{*} 10^{6} / 1\right)$ groups. The difference between the asthmatic group and the study group was not statistically significant $(0.05<\mathrm{p}<$ $0 \cdot 1)$. The asthmatic group also had higher values of total $\operatorname{IgE}($ mean $=160 \mathrm{ku} / \mathrm{l})$ than the study (mean $=$ $45 \mathrm{ku} / \mathrm{l})$ and the control $($ mean $=34 \mathrm{ku} / \mathrm{l})$ groups but the differences were not statistically significant.

Standard skin prick testing was performed in the study group with a panel of 11 common allergens (Soluprick, Nordiskt Allergilaboratorium, Copenhagen). Diluent and histamine controls were made.
Testing showed weak $2 \mathrm{~mm}$ positive skin reaction to diluted (1:100) home dust in one subject and positive skin reactions to birch and common alder in another subject in the study group. Neither had a family history of asthma or allergy, no history of atopic manifestations, and both had normal total $\operatorname{IgE}(65 \mathrm{ku} / \mathrm{l})$.

No positive skin prick test was found using albumin conjugated isocyanates. Nor did any of the study group have isocyanate specific IgE antibodies tested by radioimmunoassay test (RAST). Of 23 serum samples examined from the study and asthmatic groups, one (from the subject group) had specific IgG antibodies against methylene diisocyanate (MDI) and TDI as shown by the enzyme linked immunosorbent assay (ELISA) technique. No isocyanate specific IgM antibodies were found by ELISA.

\section{Exposure}

The study group was occupationally exposed to common isocyanates such as TDI, MDI, and hexamethylene diisocyanate (HDI). Exposure had varied in both intensity and duration and some subjects had little exposure with months in between. Our hygienist estimated the overall exposure to isocyanate to be below the current Swedish occupational standards. At most of the workplaces no measurements have been made. Exposure measurements were done at one workplace that insulated heating pipes, where personal samples in the breathing zone disclosed MDI concentrations varying between 0.014 and $0.040 \mathrm{mg} / \mathrm{m}^{3}$ air. The current Swedish occupational standard for MDI (five minute ceiling value) is $0.01 \mathrm{ppm}$ or $0.07 \mathrm{mg} / \mathrm{m}^{3}$ air. During spraying procedures with isocyanates most subjects had used active carbon filters. Exposure time for the study group was between one and 22 years (mean 6 years).

\section{Methods}

All subjects in the study group were interviewed about previous asthma and allergy in themselves or their relatives. The study group was found to be healthy by clinical examination and chest radiography. They were all skin prick tested with common standard allergens and albumin conjugated TDI, MDI, and HDI.

Static and dynamic lung volumes were measured with a Bernstein spirometer. Functional residual capacity (FRC), residual volume (RV), and total lung capacity (TLC) were determined with the multiple breath nitrogen method. ${ }^{13}$ Measurements of closing volume, closing capacity, ${ }^{14}$ and slope index ${ }^{15}$ were made with a single breath nitrogen washout method. Washout volume was determined at $2 \%$ nitrogen level in end expired air during a multiple breath nitro- 
gen washout. ${ }^{16}$

VTG was measured after washout to $2 \%$ nitrogen in end expired air at the end of exhalation. ${ }^{12}$ After a deep inhalation of oxygen the patient rebreathed in a closed lung bag system with a maximum of five breaths, thereby mobilising nitrogen trapped in the periphery of the lungs. Nitrogen concentration at the end of the rebreathing period $\left(\mathrm{FERN}_{2}\right)$ was then measured. The VTG was calculated by the formula:

$$
\mathrm{VTG}=\left(\mathrm{TLC}^{*} \mathrm{FERN}_{2}-\mathrm{FRC}^{*}\right. \text { 0.02)/0.80. }
$$

For bronchial provocation, a solution of methacholine was inhaled from a Pari nebuliser for two minutes at the concentrations $0.001 \%, 0.01 \%, 0.1 \%$, and $1 \%$. Since a $20 \%$ decrease of FEV $_{1}$ was not reached, the provocation concentration for a $20 \%$ fall of $\mathrm{FEV}_{1}\left(\mathrm{PC}_{20}-\mathrm{FEV}_{1}\right)$ was not calculated. For VTG a clinical useful methacholine provoked increase is at present not established.

The nebuliser was driven by compressed air with a flow of $51 / \mathrm{min}$ giving an output of $221 \mathrm{mg}$ $\mathrm{H}_{2} \mathrm{O} / \mathrm{min} .{ }^{17}$ The inhaled dose was thus in the magnitude of $100 \mathrm{mg}$ solution, with a $44 \%$ deposition in the periphery of the lung as measured by deposition of $99^{\mathrm{m}} \mathrm{Tc}$ in our laboratory.

After each methacholine inhalation VTG, FEV closing volume, and WOV were measured. After the last dose of methacholine, $0.3 \mathrm{mg}$ salbutamol was inhaled from a dosimeter and the lung function tests were repeated after 15 minutes.
STATISTICAL ANALYSIS

For comparison between groups, the measurements were transformed to percentage of the predicted val-\$क्ष ues calculated from reference equations including age $\Rightarrow$ and height corrections. In the tables, however, the results are presented as uncorrected measurements: 0 Comparisons between groups were made using the non-parametric Wilcoxon-Mann-Whitney test. $\overline{\bar{D}}$. Spearman rank correlation was used to analyse the dependence of the different variables on duration of exposure.

\section{Results}

Before methacholine inhalation, VTG was equal in the three groups. After the inhalation of methacholine, VTG increased in both the study and asthmatic groups (table 1), indicating increased + bronchial reactivity. After the inhalation of $0.001 \% \vec{N}$ methacholine the difference between the study and control groups was statistically significant $(p<0.05)$. $\triangle$ The difference became larger with increasing methacholine concentrations and at inhalation of $1 \%-$ methacholine there was a large difference between the study and control groups $(p<0.001)$. The increase of VTG was reversed by inhaling salbutamol. The con- $\frac{\Phi}{3}$ trol group had only a slight increase in VTG aftero inhaling $1 \%$ methacholine. No correlation was found between VTG and exposure time (Spearman's $r \stackrel{8}{\circ}$ $0 \cdot 23, \mathrm{p}=0.31$ ).

Table 1 Volume of trapped gas ( $\mathrm{ml}$ ) before and after inhaling methacholine and salbutamol

\begin{tabular}{|c|c|c|c|c|c|c|}
\hline & \multicolumn{2}{|c|}{ Study group $(n=20)$} & \multicolumn{2}{|c|}{ Asthmatic group $(n=5)$} & \multicolumn{2}{|c|}{ Control group $(n=10)$} \\
\hline & Mean & (Range) & Mean & (Range) & Mean & (Range) \\
\hline \multirow{2}{*}{$\begin{array}{l}\text { Before } \\
\text { Concentration of methacholine: } \\
0.001 \% \\
0.01 \% \\
0.1 \% \\
1 \% \\
\text { After salbutamol }\end{array}$} & 118 & $(65-166)$ & 114 & $(87-141)$ & 110 & $(71-159)$ \\
\hline & $\begin{array}{l}137^{*} \\
134^{*} \\
265^{* *} \\
545^{* * *} \\
157 \dagger\end{array}$ & $\begin{array}{l}(81-280) \\
(79-230) \\
(91-1140) \\
(121-1115) \\
(86-450)\end{array}$ & $\begin{array}{l}158 \\
175 \\
212^{*} \\
556^{* *} \\
145\end{array}$ & $\begin{array}{l}(77-338) \\
(86-309) \\
(124-425) \\
(258-981) \\
(109-186)\end{array}$ & $\begin{array}{l}100 \\
100 \\
118 \\
205 \\
106 \ddagger\end{array}$ & $\begin{array}{l}(79-127) \\
(76-142) \\
(86-171) \\
(110-368) \\
(70-137)\end{array}$ \\
\hline
\end{tabular}

Wilcoxon-Mann-Whitney test, $p$ values in comparison with the control group: ${ }^{*} p<0.05 ;{ }^{* *} p<0.01 ;{ }^{* * *} p<0.001$. $+\mathrm{n}=19 ; \ldots \mathrm{n}=3$.

Table 2 Wash out volume (l) before and after inhaling methacholine and salbutamol

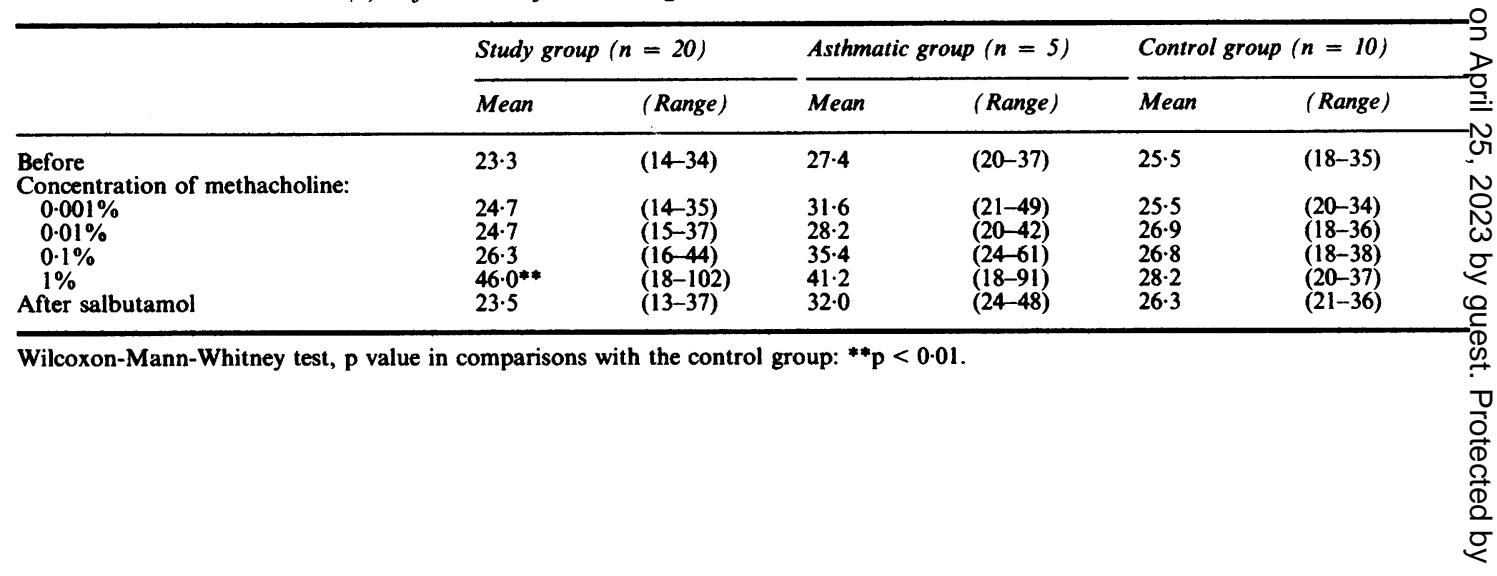


Table 3 Closing volume, closing capacity, and slope index before and after inhaling $1 \%$ methacholine and salbutamol

\begin{tabular}{|c|c|c|c|c|c|c|}
\hline & \multicolumn{2}{|c|}{ Before methacholine } & \multicolumn{2}{|c|}{ Methacholine $1 \%$} & \multicolumn{2}{|c|}{ After salbutamol } \\
\hline & Mean & (Range) & Mean & (Range) & Mean & (Range) \\
\hline $\begin{array}{l}\text { Closing volume (\% VC): } \\
\text { Study group }(\mathrm{n}=19) \\
\text { Asthmatic group }(\mathrm{n}=5) \\
\text { Control group }(\mathrm{n}=3)\end{array}$ & $\begin{array}{l}16 \cdot 6 \\
19 \cdot 8 \\
10 \cdot 3\end{array}$ & $\begin{array}{l}(9 \cdot 3-24 \cdot 5) \\
(6 \cdot 9-32.0) \\
(9 \cdot 8-10 \cdot 9)\end{array}$ & $\begin{array}{r}18 \cdot 1 \\
20 \cdot 0 \\
9.9\end{array}$ & $\begin{array}{l}(9 \cdot 7-24 \cdot 6) \\
(14 \cdot 4-31 \cdot 6) \\
(8 \cdot 6-11 \cdot 1)\end{array}$ & $\begin{array}{l}16.5 \\
15.9 \\
10.6\end{array}$ & $\begin{array}{l}(11 \cdot 7-25 \cdot 1) \\
(7 \cdot 2-23 \cdot 7) \\
(9 \cdot 9-11 \cdot 3)\end{array}$ \\
\hline $\begin{array}{l}\text { Closing capacity (\% TLC): } \\
\text { Study group }(n=19) \\
\text { Asthmatic group }(n=5) \\
\text { Control group }(n=3)\end{array}$ & $\begin{array}{l}36 \cdot 0 \\
41 \cdot 6^{*} \\
30 \cdot 1\end{array}$ & $\begin{array}{l}(22 \cdot 8-46 \cdot 4) \\
(31 \cdot 5-53 \cdot 1) \\
(25 \cdot 2-35 \cdot 0)\end{array}$ & $\begin{array}{l}39 \cdot 9 \\
42 \cdot 5^{*} \\
29 \cdot 6\end{array}$ & $\begin{array}{l}(28 \cdot 6-51 \cdot 0) \\
(33 \cdot 0-51 \cdot 3) \\
(27 \cdot 1-32 \cdot 2)\end{array}$ & $\begin{array}{l}36 \cdot 0 \\
39 \cdot 7^{*} \\
28 \cdot 6\end{array}$ & $\begin{array}{l}(26 \cdot 2-48 \cdot 7) \\
(34 \cdot 1-50 \cdot 9) \\
(24 \cdot 5-33 \cdot 3)\end{array}$ \\
\hline $\begin{array}{l}\text { Slope index }\left(\% N_{2} / 1\right) \\
\text { Study group }(n=19) \\
\text { Asthmatic group }(n=5) \\
\text { Control group }(n=3)\end{array}$ & $\begin{array}{l}0.93 \\
1.38^{*} \\
0.80\end{array}$ & $\begin{array}{l}(0.60-1 \cdot 60) \\
(0.80-1 \cdot 80) \\
(0.80)\end{array}$ & $\begin{array}{l}1.05 \\
1.56^{*} \\
0.75\end{array}$ & $\begin{array}{l}(0 \cdot 60-1 \cdot 80) \\
(0 \cdot 80-2 \cdot 80) \\
(0 \cdot 70-0 \cdot 80)\end{array}$ & $\begin{array}{l}0.84 \\
2.40 \\
0.67\end{array}$ & $\begin{array}{l}(0.40-1 \cdot 20) \\
(0.60-8 \cdot 0) \\
(0.40-0.80)\end{array}$ \\
\hline
\end{tabular}

Wilcoxon-Mann-Whitney test, $p$ value in comparisons with the control group: ${ }^{*} p<0.05$.

Table 4 FEV (l) before and after inhaling methacholine and salbutamol

\begin{tabular}{|c|c|c|c|c|c|c|}
\hline & \multicolumn{2}{|c|}{ Study group $(n=20)$} & \multicolumn{2}{|c|}{ Asthmatic group $(n=5)$} & \multicolumn{2}{|c|}{ Control group $(n=10)$} \\
\hline & Mean & (Range) & Mean & (Range) & Mean & (Range) \\
\hline $\begin{array}{l}\text { Before } \\
\text { Concentration of methacholine: }\end{array}$ & $4 \cdot 28$ & $(2 \cdot 86-5 \cdot 98)$ & $4 \cdot 14$ & $(2 \cdot 74-5 \cdot 10)$ & $4 \cdot 53$ & $(4 \cdot 00-5 \cdot 48)$ \\
\hline $\begin{array}{l}0.001 \% \\
0.01 \% \\
0.1 \% \\
1 \% \\
\text { After salbutamol }\end{array}$ & $\begin{array}{l}4 \cdot 22 \\
4 \cdot 27 \\
4 \cdot 17 \\
4 \cdot 06 \\
4 \cdot 35^{*}\end{array}$ & $\begin{array}{l}(2 \cdot 53-5 \cdot 87) \\
(2 \cdot 66-5 \cdot 95) \\
(2 \cdot 58-5 \cdot 78) \\
(2 \cdot 55-5 \cdot 34) \\
(2 \cdot 69-6 \cdot 03)\end{array}$ & $\begin{array}{l}4 \cdot 16 \\
4 \cdot 13 \\
4 \cdot 05 \\
3 \cdot 73 \\
4 \cdot 31\end{array}$ & $\begin{array}{l}(2 \cdot 82-5 \cdot 10) \\
(2 \cdot 74-5 \cdot 10) \\
(2 \cdot 80-4 \cdot 80) \\
(2 \cdot 55-4 \cdot 55) \\
(2 \cdot 91-5 \cdot 51)\end{array}$ & $\begin{array}{l}4 \cdot 55 \\
4 \cdot 57 \\
4 \cdot 55 \\
4 \cdot 51 \\
5 \cdot 02 \dagger\end{array}$ & $\begin{array}{l}(3.95-5 \cdot 59) \\
(3 \cdot 97-5 \cdot 51) \\
(3 \cdot 89-5 \cdot 65) \\
(3.84-5 \cdot 51) \\
(4.55-5.48)\end{array}$ \\
\hline
\end{tabular}

*n $=19 ; \mathrm{tn}=3$.

Wilcoxon-Mann-Whitney test, no statistically significant difference in comparisons with the control group.

Washout volume also increased after methacholine inhalation but was significant only after the inhalation of $1 \%$ methacholine (table 2). Closing volume, closing capacity, and slope index did not increase significantly in the study group. In the asthmatic group a slight increase was found after inhaling $1 \%$ methacholine compared with the controls (table 3). No large airway hyperreactivity as studied by FEV $_{1}$ was found in any of the groups, although the asthmatic group had a slight reaction at $1 \%$ methacholine. The reaction was reversed with salbutamol (table 4): Regression of $\mathrm{FEV}_{1}$, corrected for age and height, on exposure time indicated a progressive lowering of $\mathrm{FEV}_{1}$ with an increase in exposure time. The correlation was not statistically significant (Spearman's $r=0.32, p=0.17$ ).

\section{Discussion}

Our main finding is the demonstration of increased VTG after the inhalation of methacholine in a group of non-atopic symptom free lifelong non-smokers exposed to isocyanates. The other methods used for the study of small airways, such as washout volume, closing volume, closing capacity, and slope index, confirmed the small airway hyperreactivity found in the study and asthmatic groups. Since the relative changes before and after methacholine provocation were larger for VTG, we conclude that this method is more sensitive in detecting hyperreactivity in small airways. Our results also indicate that closing volume and VTG may not measure the same function in the small airways. The short time reproducibility of VTG has an error for a single determination of $8 \mathrm{ml},{ }^{12}$ and in our laboratory is $12 \mathrm{ml}$ in subjects with asthma (unpublished data).

Bronchial hyperreactivity was not found in the large airways, as measured by fall of FEV . The fall did not exceed $20 \%$ after inhaling $1 \%$ or less methacholine. This is in agreement with studies showing lack of hyperreactivity in the large airways despite a history of occupational asthma due to TDI. Nevertheless, hyperreactivity could be shown after the subjects had been exposed to TDI by inhalation challenge. ${ }^{18}$ Such exposure, even under controlled conditions, certainly entails a greater risk than using the highly sensitive VTG determination in combination with a methacholine provocation test.

The exposed workers had no history of asthma or allergy. Subjects with raised total IgE and positive skin prick tests to several common allergens were not included, thus the study group is highly selected for non-atopic subjects. We included one subject in the study group with positive skin prick tests to two common allergens. His increase of VTG to methacholine provocation was equal to the mean increase in the 
study group. As a sample, the exposed workers represent that part of the workforce exposed to isocyanate with healthy lungs, but they had nevertheless developed non-specific small airway hyperreactivity. The tendency to develop asthma is often hereditary but lack of a family history of asthma did not hinder the development of non-specific hyperreactivity.

The control group was considered to be a representative of a non-smoking non-allergic population but since the subjects were not skin prick tested, some with positive skin prick tests to common allergens might have been included.

The same degree of hyperreactivity in the small airways was present in both the symptom free nonsmoking isocyanate group and the group with previous isocyanate induced asthma. Our findings indicate that isocyanates, even at low exposures, must be considered a health hazard. Since we have controlled for smoking and allergy, we suggest that the observed difference in small airways reactivity is caused by exposure to isocyanates.

Three of the excluded subjects were tested with methacholine and all showed a pronounced increase in VTG. One of these symptom free subjects, who had a negative skin prick test but a raised total $\operatorname{IgE}$ $(120 \mathrm{ku} / \mathrm{l})$ and a mother with asthma, continued to be exposed to isocyanates and two years later developed clinical asthma. This indicates that increased VTG after methacholine provocation might be a predictor for the development of asthma.

This cross sectional study cannot predict that abnormal reactivity in the small airways in the study group may proceed to manifest obstructive lung disease. A prospective study among subjects exposed to isocyanate is necessary to determine whether such a risk exists. Nevertheless, the exposed workers, despite a lack of disease, had the same degree of hyperreactivity as the group with previously manifest isocyanate asthma.

Workers at risk from obstructive lung disease might be detected at a preclinical stage with a provocation test using methacholine and the subsequent determination of VTG. Understanding the early development of asthma is important, and more studies should be directed to diseases of small airways. It might be possible to prevent progression to clinical asthma or chronic obstructive lung disease.

We thank Mrs Rosie Wiberg-Kautto, laboratory technician, department of clinical physiology, for performing all the methacholine provocations and lung function tests; Lars Belin MD, allergy laboratory, Department of Medicine, Sahlgrenska Hospital, Gothenburg, for performing the serum RAST testing for specific IgE isocyanate antibodies, and supplying us with isocyanate conjugates for skin prick testing: Hans Welinder PhD, Department of Occupational Medicine, University Hospital, Lund, for performing the ELISA testing for specific IgG and IgM iso $\overline{0}$ cyanate antibodies; Eva Pitulainen MD, Departmentof Lung Medicine, for performing the skin prick test $-\bar{D}$ ing; Irena Cynkier $\mathrm{PhD}$, for performing the sampling and analysis of isocyanates; and Lars Wahlgren $\vec{\Rightarrow}$ Department of Computer Science, Malmö Generafo Hospital, for performing statistical calculations. Thes Swedish Work Environment Fund supported the study through grant ASF 81/1172.

Requests for reprints to: Dr Ulf Hjortsberg, Department of Occupational Medicine, Malmö Gen $\vec{\square}$ eral Hospital, S-21401 Malmö, Sweden.

\section{References}

1 Butcher BT. Isocyanate induced asthma. Eur J Respir Dis 1982;63 (suppl 123):78-81.

2 Hanna GM. Symptoms in workers exposed to isocyanates. Sug $\overrightarrow{\mathrm{N}}$ gested exposure concentrations. Arch Ind Healt $b_{0}$ 1957;16:232-3.

3 Swensson $\AA$, Andersson K. Diisocyanates. Nordic expert grou for documentation of threshold limit values. Arbete och hälsø 1985;19:20-34. (In Swedish with English summary.)

4 Venables KM, Dally MB, Burge PS, Pickering CAC, Newmad Taylor AJ. Occupational asthma in a steel coating plant. $\mathrm{Br} \mathbb{D}$ Ind Med 1985;42:517-24.

5 Butcher B. Long-term respiratory effect of isocyanate exposure Eur J Respir Dis 1982;63 (suppl 123):87-90.

6 Wegman DH, Peters JM, Pagnotto L, Fine LJ. Chronic pulmonary function loss from exposure to toluene disocyantete Br J Ind Med 1977;34:196-200.

7 Butcher BT, Karr RM, O'Neil CE, et al. Inhalation challengegnd pharmacologic studies of toluene diisocyanate (TDI) sensi远v workers. J Allergy Clin Immunol 1979;64:655-7.

8 Pham QT, Mur JM, Chau N, Gabiano M, Henquel J, Teculèsc® D. Prognostic value of acetylcholine challenge test: a prospec $\overline{0}$ tive study. Br J Ind Med 1984;41:267-71.

9 Thurlbeck W, Malaka D, Murphy K. Goblet cells in the periph $\Phi$ eral airways in chronic bronchitis. Am Rev Respir Dis, 1975;112:65-9.

10 Arborelius M Jr, Svenonius E, Kautto R. Volume of trapped gaş and maximal flow at $25 \%$ of vital capacity in exercise-induced asthma. In: Small airways in health and disease. Excerpty Medica 1979;485:21-6. (International congress series.)

11 Lichtneckert S. Volume of gas trapped in the lungs analysed bP nitrogen, elimination during oxygen breathing. Acta Univer sitatis Lundensis 1967;8:1-10.

12 Christensson P, Arborelius M Jr, Kautto R. Volume of trapped gas in lungs of healthy humans. J Appl Physiol 1981;51:172-5.

13 Svanberg L. Influence of posture on the lung volumes, ventilatioø and circulation in normals. A spirometric-bronchospirometrie investigation. Scand J Clin Lab 1957;9 (suppl 25):1-195.

14 Dirksen H, Arborelius M Jr, Lilja B. Nitrogen and ${ }^{133}$ xenon closo ing volumes in healthy non-smokers. Scand $J$ Respir Dis 1974:55 (suppl 85):233-42.

15 Oxhöj H, Bake B, Wilhelmsen L. Closing volume in 50 and $6 \overline{\mathrm{O}}$ year old men. A preliminary report. Scand J Respir Dधि 1974;55 (suppl 85):259-65.

16 Arborelius M Jr, Dirksen H, Lilja B, Lindell SE. Wash out vof ume (WOV) as a measure of ventilatory efficiency. Scand $\mathbb{W}$ Respir Dis 1974;55 (suppl 85):243-4.

17 Madsen F, Holstein-Rathlou N-H, Frølund L, Weeke B Svendsen UG. Bronchial histamine challenge in the diagnosis of asthma. Allergy 1986;41:187-95.

18 Mapp CE, Dal Vecchio L, Boschetto P, De Marzo N, Fabbff, LM. Toluene diisocyanate-induced asthma without airway hyperresponsiveness. Eur J Respir Dis 1986;68:89-95. 